\title{
HCI Challenges in Designing Game-Centric Interfaces for Autism
}

\author{
Mayank Sharma, Ayush Sharma \\ ${ }^{1}$ Chalopadho, Punjabi Bagh, New Delhi \\ ${ }^{2}$ School of Computer Science and Engineering, Jaypee Institute of Technology, Sector 128, Noida, Uttar Pradesh
}

\begin{abstract}
Game-Based learning is popular technique for boosting learning and engagement in traditional classrooms. HCI focuses on developing a deep understanding of user characteristics and tasks. As important as HCI is for designing programs used by the general public, it is even more important if the target audience is autistic learners. We designed software to be used in Tamana Autism Centre School of Hope, Delhi to enhance learning process during the computer sessions of autistic learners in the school. We gathered feedback from teachers and care-takers in the school to refine our product. The reaction of all users determined how successful we were in designing programs in such a challenging environment.
\end{abstract}

Keywords: HCI, Game-based Learning, UX, Gamified

\section{Introduction}

The computer classes of students at Tamana Autism Centre has not all involved computer software. No graphical interface was present and the techniques, while considered to be effective, were no better than paper-based exercises and activities. A new user experience was created that laid the foundations of gamified learning in computer software and classroom. This UX design implementation aims to enhance the learning experience of kids and also assists teachers to know the engagement point of the kid. The software needs to be repeatedly used and enjoyed both by children and teachers. The challenges to designing and implementing such a software are significant, particularly given the wide range of child behaviours and emotions.

The activities were analysed and restructured; they were significantly enhanced and new features were iterated. The principles of cognitive psychology, learning and UX design were all incorporated in the design process. Care-takers and different subject teachers were constantly involved while designing the application and feedback was taken at each design phase. At the moment, software is currently in beta version and is used by Tamana School of Hope.

We report here on the process of developing Exell from the point of view of HCI issues was they relate to this special set of users : autistic children and their respective teachers and care-takers. While many items can be considered mainstream in the literature, their importance was enhanced by the special needs of the user group.

\section{Requirements}

$\mathrm{HCI}$ is user centred and accentuates the need for designing the visual representation of the program before focussing on the computing itself. A good user experience and interface is extremely important for this group of autistic children and their supporting teachers. Previously computer sessions for the autistic kids in the school only involved obsolete learning methodologies and software. Being deprived of such technologies, they had no choice but to use generic paint and document editing programs. Since the goal is to enhance learning experience and engagement of autistic kids, the kids are prone to mood swings and frustration, so simplicity and playfulness is critical to the design. These software will be designed in such a way that they can be customised as per the needs of teachers and curriculum. So, to design such experiences we must understand the way they are thinking, the cause if their actions, their feelings, everything about them that helps us to build a product that meets their needs.

Following are the characteristics of kids that can help in the design of game-based experience -

- The autistic brain doesn't comprehend the incoming information very well.

- People with autism tend to perceive every detail and each little nuance with same intensity.

- Autistic kids are fond of things that are fixed, the daily routines, or already known informations.

Issues that are common to almost all disengaging experiences are that children have fear of failing in short quizes(they might even cry), they shouldn't be distracted, they need to focus on fixed things, and they should have some kind of interactive interface with them with which they can interact constantly. Their were also some specific issues like learning and memory deficits, lack of control over emotions and behaviour and difficulties in grasping information etc. There were also difficulties in performing activities that required multiple level of complexities or required multiple operations.

Study of the principles of cognitive psychology, HCI and software engineering helped to determine the overall principles of good program design for the general population. Those identified principles were then examined with respect to this specific child population. There was an increased emphasis 


\section{International Journal of Science and Research (IJSR) \\ ISSN (Online): 2319-7064 \\ Index Copernicus Value (2013): 6.14 | Impact Factor (2014): 5.611}

placed on ease of use over all other considerations, as it was determined that simplicity of design was of paramount importance.

Along with the principles of HCI, key elements of game-based learning like leaderboards, point and badge system and use of game for learning were also implemented.

\section{Design Issues and Feedback}

We tried to design software that had consistent and limited options. Limitations were learnt from the routinely observation and interaction with the care takers and the children which gave us insights about more generic HCI paradigms for autistic people.

Primary design issues were identified:

1) Use of bigger and clear graphic elements i.e. fonts, buttons, icons etc.

2) Use of contrasting colours. One kid was observed using Black and Red colour palette while using the paint program.

3) Using audio- visual text While giving an classroom exercise on English, teacher used images to make them answer simple "Fill in the blank" questions like, "
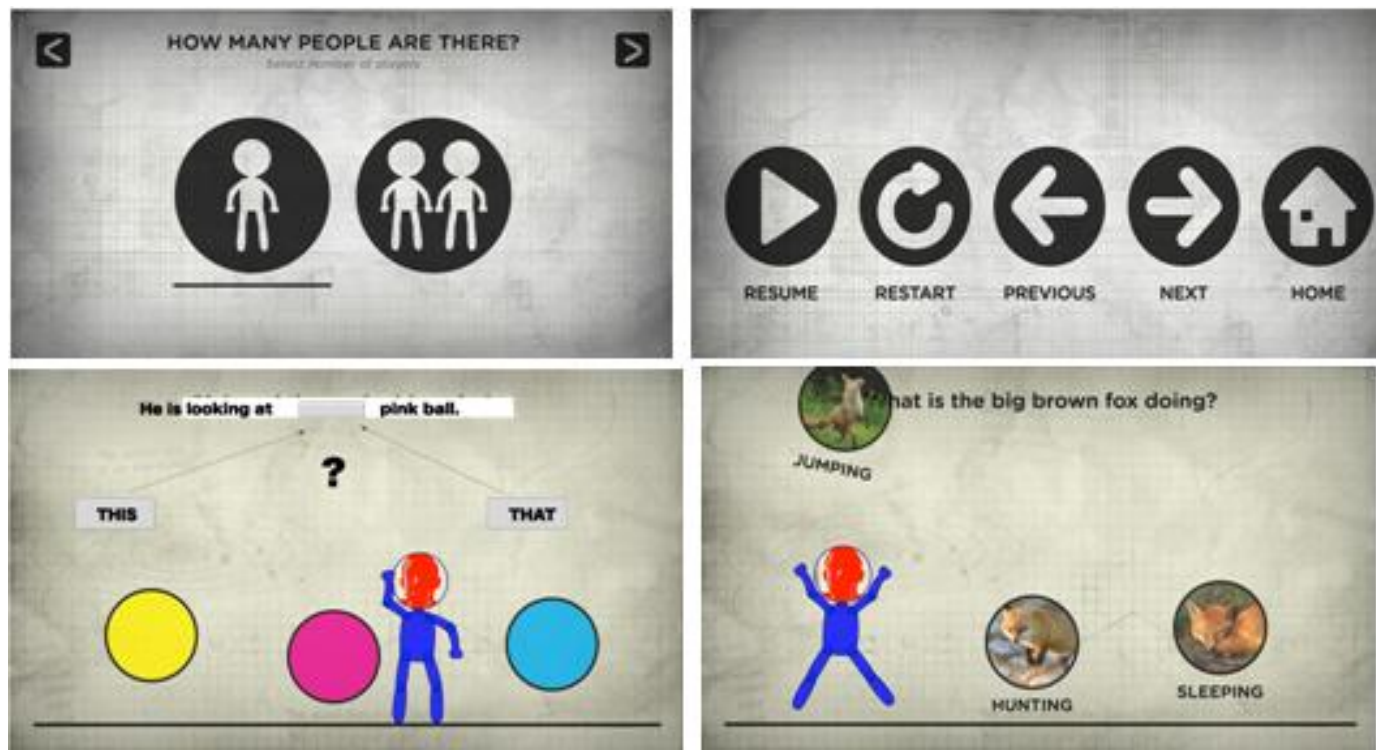

Figure 1.1

At the opening of the application, the users select their avatar which takes their image(as shown in Fig.1.1) and adds that to red face as shown. Once the avatar is selected, the user selects number of players (single-player/multiplayer). Child has to select the appropriate option my dragging towards the desired blank. So this fill in the blank game can use the same content the teacher uses to teach kids on the black board. The game metaphor proved to be a winning strategy as it combined ease of use, the simplicity, effective and bolstered the engagement. is a chair." (Answer here is "That" and teacher used a far image of an object to illustrate the use of "that" in english)

4) Avoid multiple tasks.

5) Trying connecting the image with their daily lives.

6) Avoid didactic information.

7) Avoid the situation that traps a kid to which might make them frustrated.

8) Use of both languages - English and Hindi.

\section{Strategy}

The main strategy was to incorporate a game-based environment which was based on points and leaderboards.This strategy was implemented along with design thinking approach.

\subsection{User Experience Research}

We used qualitative research based interviews to understand the teaching experience and problems of caregivers, which included the parents and teachers of children with autism.

\subsection{User Experience Design}

Based on the research, various prototypes were developed and a new learning game was designed for teachers and students. Screenshots of the program are given as follows:
When a user chooses to play game, a screen of instructions appears at first, yet always completely consistent in their layouts. The "Previous", "Home", "Next", "Restart" buttons are always in the same locations on the board and directly accessible, and are integrated within the functionality. For example, if the Help button is pressed while an activity is running, the timing clock continues to count. 


\section{International Journal of Science and Research (IJSR) \\ ISSN (Online): 2319-7064}

Index Copernicus Value (2013): 6.14 | Impact Factor (2014): 5.611

\subsection{User Testing}

The care givers of children consisted of parents and special education instructors. We examined the problems experienced by the teachers and students when using existing traditional teaching materials. During the 6-week deployment, each caretaker and teacher were interviewed. Interview discussed how they were able to utilise the system and the response of the kids was also observed.

\subsection{Feedback}

Main changes made as a result of feedback were made as follows:

1) Colour Stimuli : Using contrasting colour choices. Red and white.

2) Font size: Use better and bold texts.

3) While pre-processing information, Gestalt laws were applied and also using small details consistently is a great help, i.e. a little shadow on components that need to be interacted with, or dotted borders to mark placeholders.

4) Points system - Points were awarded for every correct move. However, no points were deducted for the wrong move. Repetition was used until child gets to the right answer.

5) Using little predictable routines so as to make it more predictable (click,click,click)

\section{Conclusion}

The current design process is human-centered design and game based learning, emphasising both theory and practice. With the development of low cost programming, the whole process can be shortened to fulfil the needs of a research project. Therefore, we can have a new kind of design study that combines both qualitative and quantitative design research and results to obtain both better research-based design and better research through design. This paper illustrates the possibilities and process of this new kind of design study with the design process of an app aimed at assisting the teaching of autistic children. We believe that in the future, this may be one of the best design study practices. Furthermore, with the development of rapid prototyping, the lower cost of modifying physical products will enable the application of this new design study to products other than software. All kinds of design may use this method.

\section{References}

[1] Winograd, T. (1996) Bringing Design to Software. ACM Press, Reading, Mass. And Addison-Wesley.

[2] Mullet, K. (1995) Designing Visual Interfaces: Communication Oriented Techniques. SunSoft Press.

[3] Collins, D. (1995) Designing Object-Oriented User Interfaces. Benjamin-Cummings.

[4] Batista, C., Ulbricht, V., Gonçalves, M., Vanzin, T., \& Filho, A. (n.d.). Inclusive Design: An Interface for Users with Disabilities. HCI International 2014 - Posters'
Extended Abstracts Communications in Computer and Information Science, 214-219.

[5] Muzio, J., \& Serra, M. (2001). HCI Challenges In Designing for Users with Disabilities. Int. Conf. On HCI, 1, 46-50.

[6] Research-based design and research through design: A case study of the improvement in the user experience of an autism caregiver using ICT. (2014). Retrieved from http://www.drs2014.org/media/654257/0273-file1.pdf

[7] R. Hayes, G. (n.d.). Understanding Educational Technology through Special Education and Autism. Retrieved from http://www.gillianhayes.com/wpcontent/uploads/2011/01/17_AAA_Autism.pdf

[8] Game Collections - Autism Games. (n.d.). Retrieved December 2, 2015, from https://sites.google.com/site/autismgames/home/gamespages

[9] Design for autism. (2015, April 17). Retrieved December 2, 2015, from https://medium.com/@samuvagyok/design-for-autismbf27e5528cec\#.pyikbeu5i 